\title{
Modelling energy demand of Croatian industry sector
}

\section{Zlatko Bačelić Medić and Tomislav Pukšec*}

Department of Energy, Power Engineering and Environment, Faculty of Mechanical Engineering and Naval Architecture, University of Zagreb, Ivana Lučića 5, 10000 Zagreb, Croatia

E-mail: zlatko.bacelic.medic@fsb.hr

E-mail: tomislav.puksec@fsb.hr

*Corresponding author

\section{Brian Vad Mathiesen}

Department of Development and Planning,

Aalborg University,

A.C. Meyers Vænge,

DK-2450 Copgenhagen SV, Denmark

E-mail: bvm@plan.aau.dk

\author{
Neven Duić \\ Department of Energy, Power Engineering and Environment, \\ Faculty of Mechanical Engineering and Naval Architecture, \\ University of Zagreb, \\ Ivana Lučića 5, 10000 Zagreb, Croatia \\ E-mail: neven.duic@fssb.hr
}

\begin{abstract}
Industry represents one of the most interesting sectors when analysing Croatian final energy demand. Croatian industry represents $20 \%$ of nation's GDP and employs $25 \%$ of total labour force making it a significant subject for the economy. Today, with around $60 \mathrm{PJ}$ of final energy demand it is the third most energy intensive sector in Croatia after transport and households. Implementing mechanisms that would lead to improvements in energy efficiency in this sector seems relevant. Through this paper, long-term energy demand projections for Croatian industry will be shown. The central point for development of the model will be parameters influencing the industry in Croatia. Energy demand predictions in this paper are based upon bottom-up approach model. IED model produces results which can be compared to Croatian National Energy Strategy. One of the conclusions shown in this paper is significant possibilities for energy efficiency improvements and lower energy demand in the future.
\end{abstract}

Keywords: energy demand; industry; modelling; Croatia. 
Reference to this paper should be made as follows: Medić, Z.B., Pukšec, T., Mathiesen, B.V. and Duić, N. (2014) 'Modelling energy demand of Croatian industry sector', Int. J. Environment and Sustainable Development, Vol. 13, No. 1, pp.74-92.

Biographical notes: Zlatko Bačelić Medić finished Ruđer Bošković High School in Zagreb in 2004 and started his studies on the Faculty of Mechanical Engineering and Naval Architecture. In 2012 he successfully completed the studies and obtained the MSc title in Mechanical Engineering with specialisation in Energy. He worked during his studies on the faculty on various European funded projects and in 2010 started working for a private company in which he remains employed up to now.

Tomislav Pukšec is a Research Assistant and a PhD student at the Faculty of Mechanical Engineering and Naval Architecture, University of Zagreb. He is author of 15 scientific papers and a member of The International Centre for Sustainable Development of Energy, Water and Environment Systems (SDEWES Centre). He is a Croatian Science Foundation scholar.

Brian Vad Mathiesen is an Associate Professor in Energy planning at the Department of Development and Planning, Aalborg University. He serves as a Deputy Head of 4DH Research Centre. He is the author of 17 papers in refereed international journals, 14 papers and presentations in international proceedings, 20 reports, books, book chapters etc., eight popular articles and essays.

Neven Duić is a Full Professor at the Power Engineering and Energy Management Chair at the Department of Energy, Power Engineering and Environment, Faculty of Mechanical Engineering and Naval Architecture. He has published over 150 research papers, of which 53 in journals (of which 39 in journals refereed in SCI) and six in books. He was cited 461 times in Scopus and 288 times in WoS. He gave more than 50 invited and keynote lectures.

This paper is a revised and expanded version of a paper entitled 'Modelling energy demand of Croatian industry sector' presented at The 7th Conference on Sustainable Development of Energy, Water and Environment Systems SDEWES Conference, Ohrid Macedonia, 1-7 July 2012.

\section{Introduction}

Demand side management is an integral part of energy planning and an input operation towards advanced systems analysis (Ćosić et al., 2011; Krajačić et al., 2011). In order to analyse future energy systems, one needs to predict future energy demand in a most precise way. The preparation of data for an investigation of a $100 \%$ renewable energy system includes detailed resource mapping and detailed assessment of all energy consuming activities (Segurado et al., 2011; Connolly et al., 2011; Ćosić et al., 2012; Liu et al., 2011; Klemeš et al., 2010). Post carbon societies as well as sustainable energy systems are not possible without rational energy demand planning.

Industry sector presents the second largest energy consumer worldwide (IEA, 2010), with the highest expected yearly growth rate till 2030. Having that in mind, analysing and implementing measures or technologies that might lead to a decrease in energy 
consumption seems relevant (Paulus and Borggrefe, 2011). Demand side management is the first step in achieving that goal. Modelling energy demand and analysing different approaches and scenarios point out activities which, if applied, could contribute to reduced energy consumption, mitigation of GHG emissions and increasing the security of energy supply (Szabó et al., 2009).

When analysing energy consumption of Croatian industry sector for the last 20 years, significant decrease can be detected beginning of 1990s; from almost $100 \mathrm{PJ}$ of final energy demand in 1989 to less than $50 \mathrm{PJ}$ in 1995. This decrease is a direct result of war, changes in the structure of governance, inability of transforming old industrial operations to new technologies and markets as well as Croatian tendency towards tertiary sector activities. After 1995 energy consumption of Croatian industry sector has grown steadily until recent years when it was affected by the economic crisis in 2009 with a yearly decrease in energy consumption of more than $16 \%$ (Vuk et al., 2009).

Modelling long-term energy demand of an industry sector presents a challenge because of all specific characteristics and different exogenous factors that directly influence energy consumption (Fleiter et al., 2012). In order to tackle these issues different approaches, or philosophies, in energy demand modelling have been developed, with two most common being top-down and bottom-up approach (Fleiter et al., 2011). Top-down models tend to observe energy systems or sectors on an aggregated level by establishing interaction between energy demand and economic variables, such as GDP, prices, employment or population. They can handle or predict different kind of market distortions which could influence energy demand significantly (Suganthi and Samuel, 2012). However, the downside of these models is their inability of quantifying technology impacts as well as different legal or financial measures in a more detailed way (Fan and Xia, 2012). This paper focuses on presenting long-term energy demand of Croatian industry sector by using bottom-up approach predominately. But in order to describe additional variables specific to industry sector, some aspects of top down approach were used. This was done in order to have a wider scope of all industry sub-sectors including technologies but at the same time for instance have the impact of imports or exports on final energy demand. As a final result of these efforts 'industry energy demand model' (IED model) has been developed. Bottom-up models are usually accounting, optimisation or simulation based (Hainoun et al., 2006). IED model can be classified both as accounting or simulation model, with a lot of required input data which is afterwards systemised and processed (Bhattacharyya and Timilsina, 2010). Optimising models work based on minimising cost of the energy system. Usually, they combine both demand as well as supply side by confronting them in order to find the cheapest solution (Dutta and Mukherjee, 2010). IED model does not have a price component so it cannot be used as an optimising tool but rather as a tool for assessing possible future outcomes dependent on chosen input parameters.

\section{Methodology}

\subsection{Methodological frame}

The IED model will be used for long-term energy demand modelling in the industry sector based on input parameters. There are four major parameters, when it comes to 
energy demand projections, covered through IED model. Special focus is given to export/import component which determines the ratio of domestic production capacities resulting in changes in energy demand. Phasing out or introducing certain type of industry also plays an important role because these changes can significantly influence the energy demand and the best example of phasing out is the textile industry which has almost completely disappeared in Croatia. Technology and efficiency component is considered in order to examine the influence of technological advancements on future energy demand. General structure of IED model is presented in Figure 1.

Figure 1 IED model (see online version for colours)

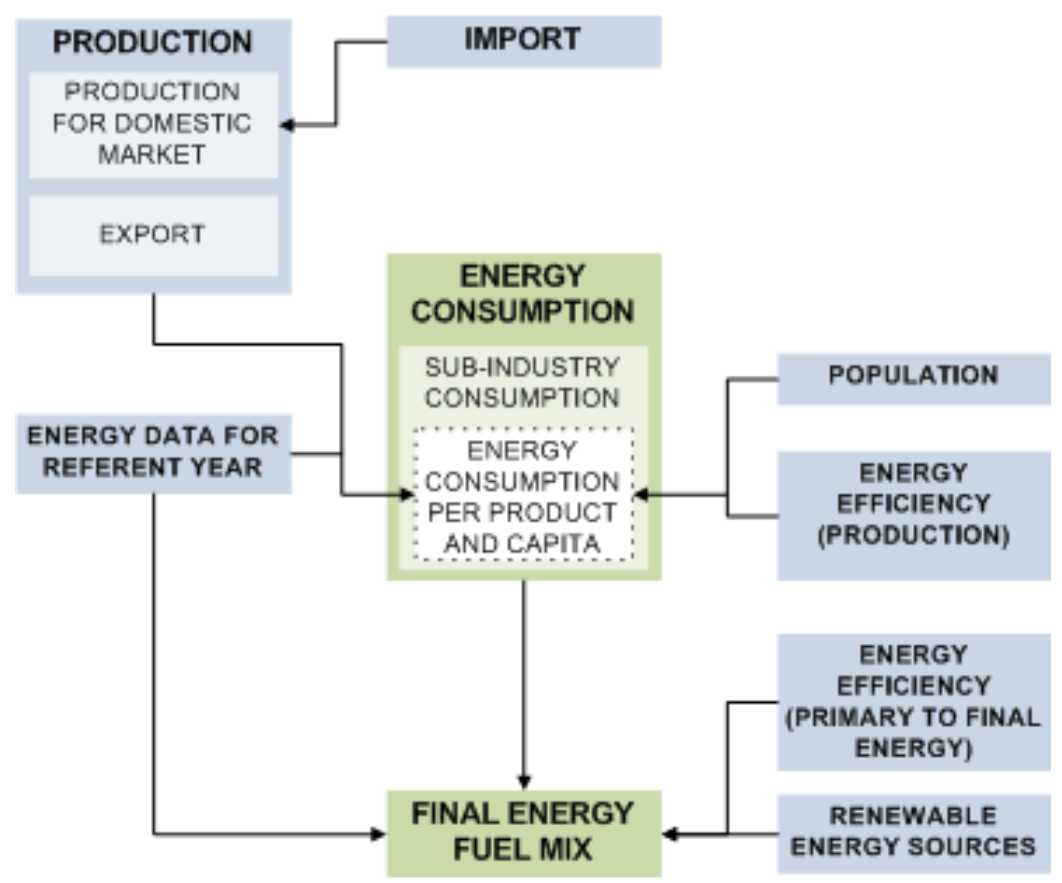

The last major parameter is the fuel mix which provides the opportunity to further improve the future energy demand according to assumptions related to phasing out of some fuels and adding new more environmentally friendly alternatives as well as renewable energy sources. All four parameters are tested in the reference year in order to verify the suggested methodology which will be used later on for future energy demand predictions. Energy balances for the reference year are available (Energy in Croatia, 2008) and can be used as an output data check. That way, any missing or unknown variables could be retrieved backwards. IED model divides industry sector in eight sub-sectors which are later on covered separately in order to describe all specific outcomes that might appear. The sub-sectors are:

- $\quad$ chemical industry

- construction materials industry 
- food industry

- iron and steel industry

- non-ferrous metals industry

- non-metallic minerals industry

- $\quad$ paper and pulp industry

- other manufacturing industries.

This methodology follows the official Croatian energy balance in order to have the possibility of modelling and obtaining the correct figures in the reference year. After testing, the IED model will be used to provide several possible future outcomes, i.e., scenarios to explore the variations in the final energy demand. The energy demand of each industry sub-sector yields an in-detail overview of barriers, specific energy related issues and opportunities which arise from current and future developments of Croatian industry sector. Another important objective of this paper is to compare results with the official energy demand scenarios presented in Croatian National Energy Strategy. The economic crisis influenced the whole industry causing a significant downfall in energy demand which means that the Croatian national energy strategy should be adapted to the new situation.

\subsection{Reference year}

The reference year was chosen to be 2008 due to absence of economic disturbance with objective to obtain valid data related to energy consumption and industrial production in average conditions. Of course, the coming periods from 2010 to 2012 have been highly influenced by the economic crisis.

Final energy consumption share of the industry sector is shown in Figure 2. The construction materials industry participates in total final energy consumption with a significant amount of $35 \%$, followed by food industry with $19 \%$, chemical industry with $17 \%$ and grouped - other manufacturing industries with $15 \%$. All other industries, such as iron and steel industry, non-ferrous metals industry, non-metallic minerals industry and paper and pulp industry have a total share of $16 \%$ in total final energy consumption of the industry sector.

Industry specific issues are in most cases related to inefficient production due to obsolete equipment used in the production process together with industry specific energy sources. The downfall of Croatian industry is heavily influenced by ongoing economic crisis in most sectors, apart from paper and pulp industry where a steady growth is noticed. Final energy consumption of the industry sector has fallen significantly when observing the amounts stated in 2010 in comparison with 2008. A downfall of $17.8 \%$ in final energy consumption has been noticed. Market conditions in combination with the weak financial situation and lack of solvency have caused significant reduction of energy consumption in majority of industrial sub-sectors. 
Figure 2 Final energy consumption share of the industry sector in Croatia, 2008 (see online version for colours)

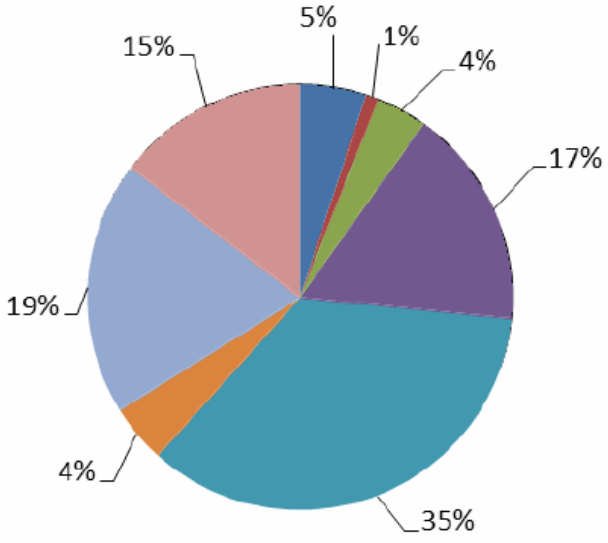

aIRON AND STEEL INDUSTRY

a NON-FERROUS METALS INDUSTRY

$\square$ NON-METALLIC MINERALS INDUSTRY

$\square$ CHEMICAL INDUSTRY

$\square$ CONSTRUCTION MATERIALS INDUSTRY

$\square$ PULP AND PAPER INDUSTRY

$\square$ FOOD INDUSTRY

口 OTHER MANUFACTURING INDUSTRIES

As the construction sector came to a stagnation period around 2008, the unexpected market disturbance due to economic crisis caused a significant drop in the construction materials industry which amounts to downfall of final energy consumption in 2010 in comparison to the referent year. A similar, devastating effect has also happened in non-ferrous metals industry where a downfall has been noticed.

\subsection{IED model - input data}

\subsubsection{Population}

For a complete overview of the Croatian industry sector, fluctuation of population had to be considered due to influence on overall domestic production in all sectors. Input parameters for further consideration have been obtained from Croatian Bureau of Statistics. Approximate trends of population change have been setup differently considering a smaller population decrease. The visible trend in Croatia shows that the majority of population tends to move to bigger population centres.

Population $\left(N_{C A P}\right)$ for each respective year is used for calculating amounts of products per capita for each industry and later for obtaining results in production planning.

\subsubsection{Production capacities}

Domestic production capacities (including products for domestic market and export) have been obtained for each industry from Croatian Bureau of Statistics for the referent year. This information allows user to calculate amounts of products per capita whose change will be later used to modify production capacities for domestic market along with import shares for each industry.

\subsubsection{Final energy consumption}

Final energy consumption data for each industry, according to previously shown classification, has been obtained from Vuk et al. (2009). This data is used in further calculation modules to obtain specific energy consumption of each industry. 


\subsubsection{Primary energy consumption}

Primary energy consumption data has been obtained from Croatian Bureau of Statistics to enable the user to manipulate the energy mix but steady change in fuel mix is expected. Primary energy consumption and primary energy mix is also used for obtaining the corresponding final energy mix including application of renewable energy sources.

\subsubsection{Consumption per capita}

Consumption per capita has been integrated in this model with the purpose to incorporate the influence of population on product consumption. Consumption per capita in referent year has been taken as a starting point for future periods modelling. Calculation is applied to each industry to obtain detailed results for the main structure. Referent year values have been calculated as:

$$
Q_{P, C}=\frac{Q_{P, D}+Q_{I}}{N_{C A P}}
$$

where $Q_{P, C}$ is the quantity of each product per capita, $Q_{P, D}$ is the total production quantity of each product for domestic market, $Q_{I}$ is the total import quantity of each product and $N_{C A P}$ is the total population. Previously shown equation is first applied to the referent year to establish a starting point.

Values ranging for other periods are calculated as:

$$
Q_{P, C x}=Q_{P, C} \cdot\left(1+i_{x}\right)
$$

where $Q_{P, C x}$ is the quantity of each product per capita and $i_{x}$ is the defined change in consumption per capita. Herein, $i_{x}$ has a significant impact on energy consumption data, therefore changes in economic development can be presented in detail.

\subsubsection{Production for domestic market and import}

Production for domestic market and import are directly linked which means that the user can, through making changes in import trends, significantly influence the production situation for domestic market. Such link adds certain flexibility to the model where exact shares can be set. However, the market situation in some industries is rather difficult to change due to small energy consumption. The highest impact on energy consumption is expected in industries where the share of domestic production is rather high and the consumption of product changes.

Production for domestic market is calculated as:

$$
Q_{P, D x}=Q_{P, C x} \cdot\left(1-i_{I, x}\right) N_{C A P}
$$

where $Q_{P, D x}$ represents the quantity of each group of products for domestic market in each year, $Q_{P, C x}$ is the specific product consumption per capita in each year, $i_{I, x}$ is the import share for specific industry and $N_{C A P}$ is the total population. Consequentially, production plans for each industry up to 2050 are made, including production for domestic market which enables the calculation of energy demand.

The import quantities were calculated as:

$$
Q_{P, L x}=Q_{P, C x} \cdot i_{I, x} \cdot N_{C A P}
$$


where $Q_{p, I x}$ represents the import quantity of each group of products with $i_{I, x}$ and $N_{C A P}$ as in the formula in production for domestic market.

\subsubsection{Production for export}

Production for export is directly regulated through determining amounts of export quantities for the referent year, which were obtained from Croatian Bureau of Statistics, and export change in the future periods. Controlling the export in this manner allows one to fully cover all possible outcomes of the energy consumption, whether the trend is rising or falling. The exact amounts of production quantities determine the flexibility of export control. For example, some industries have small or very small export quantities, therefore if one was to examine the influence of increase of export quantities for purposes of generating additional energy consumption, previously imported data should be examined to determine the necessary value of increase to display a significant change in respective industry. Additional flexibility of the designed model for export planning is obtained through separation of industry to branches where separate change trends can be set.

Production for export in periods that are predicted is calculated on the basis of the referent year, multiplied by the set change in the observed year.

$$
Q_{P, E x}=Q_{P, E, x-1} \cdot\left(1-i_{E, x}\right)
$$

where $Q_{P, E x}$ represents the export quantity of a product in the observed year, $Q_{P, E x-1}$ represents the export quantity of a product in the previous year and $I_{E, x}$ represents the change in export quantities for the observed year in comparison to the previous year.

\subsubsection{Specific energy consumption}

Specific energy consumption in the referent year is calculated from final energy data for each respective industry. This parameter directly influences final energy consumption of each respective industry, while taking into account the energy efficiency parameter. Energy efficiency has been setup as an input parameter where one can define the desired amount of increase in desired period starting with the referent year. The distribution of percentages throughout the setup period will be linear.

$$
E_{S P, \text { ind }}=\frac{E_{\text {ind }}}{P_{D O M}}
$$

where $E_{S P \text {,ind }}$ represents the specific energy consumption of industry, $E_{\text {ind }}$ represents the total final energy consumption of each industry and $P_{D O M}$ represents the total amount of products produced within the industry, including both product quantities for domestic market and product quantities for export.

\subsubsection{Increasing or decreasing energy demand}

As previously explained, the total energy consumption of each industry throughout the observed period is calculated by taking into consideration the specific energy consumption for each industry together with consumption data per capita and population for each year. Also, the final energy consumption is influenced by the possibility to 
include new industrial plants or simulate closing of existing plants, both of which are expected disturbances in all industrial sectors. Addition or removal of plants is executed is such way so that the defined parameters influence final energy consumption in the selected year, as well as in the following periods, thus allowing to directly manipulate growth or downfall of specific industry sub-sector.

\subsubsection{Renewable energy sources}

When determining all influential factors that will shape the future final energy demand, renewable energy sources must be considered as a serious alternative for conventional energy sources. The model has been setup to incorporate energy from renewable energy sources in each respective industry sub-sector. The exact increase in energy gained from renewable energy sources is an input parameter which is distributed in a linear fashion throughout the observed period. The calculation of energy gained from renewable energy sources was performed by calculating ratios of each fuel in final energy demand and multiplying the ratio by previously set increase in energy gained from renewable energy sources and final energy demand of each industry sub-sector in the referent year.

\subsection{Energy demand projection}

Total energy demand of each industry is calculated according to assumptions by taking into account several possible outcomes, i.e., scenarios. An overview of variables for each scenario is presented in the Table 2.

The first scenario is assumed to be 'business as usual' where current trends of slow growth or even slight decline are applied. The scenario envisages growth of imported goods by $15 \%$ by 2050 with slight rise of consumption per capita which amounts to $3 \%$ for each sub-sector of industry and $6 \%$ growth of export quantities. Also, final energy consumption is expected to drop by $4 \%$ by 2030 and further $6 \%$ by 2050 by implementation of energy efficiency measures in the industry sector. It has been envisaged that utilisation of renewable energy sources will reduce the energy consumption by $7 \%$ by 2050 .

Table 2 IED model input parameters for respective scenarios and modelling up to 2050

\begin{tabular}{lccccc}
\hline Scenario & Scenario 1 & Scenario 2 & Scenario 3 & Scenario 4 & Scenario 5 \\
\hline $\begin{array}{l}\text { Import change } \\
\begin{array}{l}\text { Consumption per } \\
\text { capita }\end{array}\end{array}$ & $15 \%$ & $9 \%$ & $-2 \%$ & -6 to 5\% & -6 to $5 \%$ \\
$\begin{array}{l}\text { Export } \\
\text { Energy efficiency }\end{array}$ & $6 \%$ & $6 \%$ & $6 \%$ & $51 \%$ & $36 \%$ \\
$\begin{array}{l}\text { Renewable energy } \\
\text { sources }\end{array}$ & $7 \%$ & $11 \%$ & $17 \%$ & $52 \%$ & $36 \%$ \\
\hline
\end{tabular}

Other scenarios have been obtained by changing variables to determine the sensibility of the system, determine the influence of each variable and observing the possible outcome of all changes made to the model. For instance, the second scenario envisages smaller import growth ( $9 \%$ by 2050$)$, also with bigger growth of consumption per capita (6\%) and bigger growth of exported goods (11\% by 2050). Reduction of energy consumption due to application of energy efficiency measures in this case remains the same as in 
previous described scenario, but with slightly larger growth of energy produced from renewable energy sources ( $9 \%$ by 2050$)$.

Scenario 3 predicts a slight fall of import $(2 \%)$ in overall industry sector with an increase in quantities of exported goods of $17 \%$ by 2050 . Reduction of energy consumption due to implementation of energy efficiency measures remains at the same level as in previous two scenarios. Share of renewable energy sources is increased to $14 \%$ in this scenario.

Scenarios 4 and 5 are significant because they present the situation in which the share of imported goods drops to $10 \%$ in overall product consumption. In these scenarios, such assumption will definitely have an impact on energy demand of industry sector. To achieve an even bigger effect, consumption of goods per capita is also set to rise by $51 \%$ in Scenario 4 and 36\% in Scenario 5. The main differences between these two scenarios are made in predicted increase rates of exported goods, which in case of Scenario 4 amounts to $52 \%$ and in the case of Scenario 5 to $36 \%$. Also, a difference has been made in implementation of energy efficiency measures between Scenario 4 and Scenario 5, $10 \%$ and $18 \%$, respectively, and implementation of renewable energy sources, $32 \%$ and $18 \%$, respectively.

\section{Results and discussion}

\subsection{Comparison of IED model results to Croatian Energy Strategy}

This section will summarise the obtained results through presentation of setup scenarios and trends that were defined with previously explained variables. As a first reference, Croatian Energy Strategy from 2009 (Energy in Croatia, 2008) is used to examine the results obtained from IED model and data as predicted in the strategy. The assumption is that the predictions of the Croatian Energy Strategy could be outdated because of the recent economic crisis and the obvious decrease in energy consumption (Table 1). The Croatian Energy Strategy contains two scenarios for industry, one being 'business as usual' scenario (referred to as S1-CES) and the other 'sustainable scenario' (referred to as S2-CES) in which all goals defined in the Croatian Energy Strategy have been included. Those goals incorporate the increase in energy efficiency, increase in renewable energy sources share and implementation of distributed energy sources.

Two scenarios obtained from Croatian Energy Strategy were compared to the IED Scenario 1. Scenario S1-CES is considered to be the 'business as usual' scenario in Croatian Energy Strategy and is rather unrealistic, especially due to recent market disturbances caused by economic crisis (Croatian National Energy Strategy, 2009). Scenario S2-CES, or 'sustainable scenario' envisages energy demand of Croatian industry sector with application of energy efficiency measures and economically viable renewable energy sources.

As it can already be seen in 2010, a difference between IED Scenario 1 and the S2-CES of almost $23 \%$ is visible. As predicted, in 2030 the difference between SC2-CES and the designed model Scenario 1 grows up to $126 \%$. If comparing IED Scenario 1 with the S1-CES in 2030, the difference grows up to $140 \%$. It is instantly visible that the Croatian Energy Strategy must be taken with a certain reserve considering all possible parameters that might influence future energy demand. This uncertainty simply proves that the energy strategy must take into consideration all influential factors in the industry 
as well as the comprehensive analysis of the energy data sector by sector. Of course, market disturbances such as economic crisis cannot be predicted in an accurate fashion but such occurrences must be taken into account. The large discrepancies are a result of many assumptions in IED model as well as the Croatian Energy Strategy.

Table 1 Final energy consumption in Croatian industry sector, 2008-2010

\begin{tabular}{lccc}
\hline \multirow{2}{*}{ Industry sub-sector } & \multicolumn{3}{c}{ Final energy demand [PJ] } \\
\cline { 2 - 4 } & 2008 & 2009 & 2010 \\
\hline Iron and steel industry & 3.08 & 2.34 & 2.67 \\
Non-ferrous metals industry & 0.60 & 0.55 & 0.47 \\
Non-metallic minerals industry & 2.36 & 2.37 & 2.42 \\
Chemical industry & 10.23 & 9.18 & 8.55 \\
Construction materials industry & 21.47 & 16.35 & 15.09 \\
Pulp and paper industry & 2.72 & 2.77 & 3.04 \\
Food industry & 11.80 & 9.46 & 9.95 \\
Other manufacturing industries & 8.92 & 8.10 & 8.11 \\
\hline Total industry & 61.18 & 51.14 & 50.31 \\
\hline
\end{tabular}

Figure 3 presents the Croatian Energy Strategy scenarios in comparison with the designed model scenarios where a decline of energy demand up to 2050 is expected in Scenario 1 and Scenario 2 and a slight rise in IED in Scenarios 3, 4 and 5.

Figure 3 Final energy demand projections comparison between two Croatian Energy Strategy scenarios and the IED model Scenario 1 (see online version for colours)

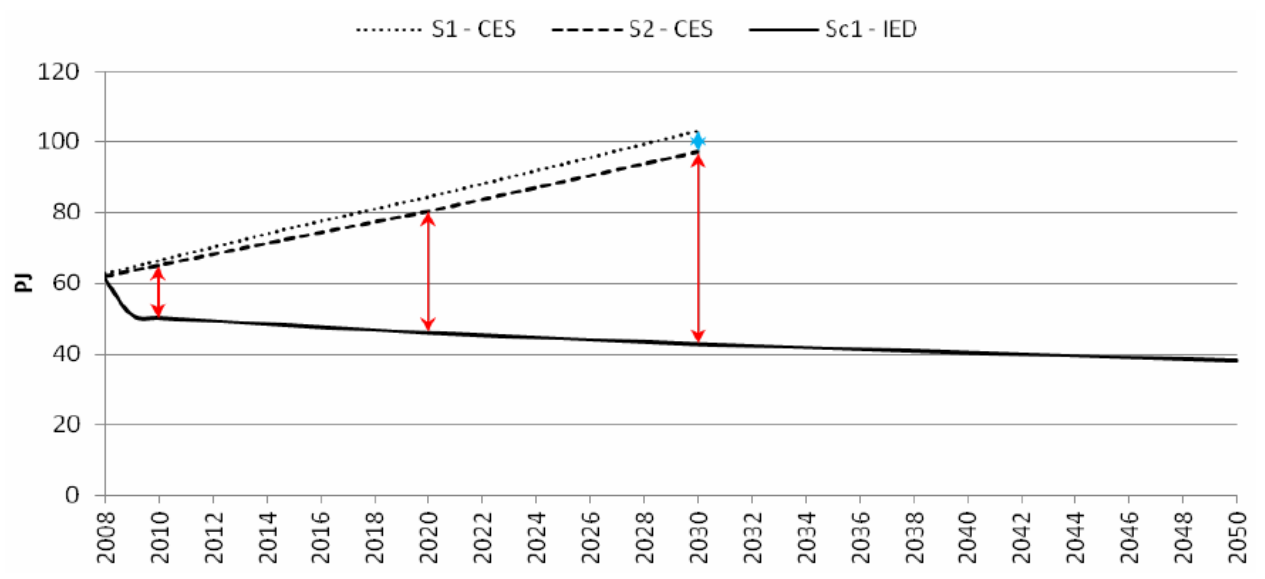

\subsection{IED model scenario results}

It must be noted that all modelled scenarios yield results in which the recovery of industry sector, visible from final energy demand in Scenarios 3, 4 and 5, happens at around 2020. On the other hand, Scenarios 1 and 2 point out that the complete recovery 
may not occur. Such outcome is highly probable, especially with implementation of subsidies for energy efficiency measures and renewable energy sources in industry and many break-through technologies becoming economically viable. Of course, many other relevant factors will influence and shape the future final energy demand of the Croatian industry sector.

\subsubsection{Energy produced from renewable energy sources}

Apart from energy efficiency measures, renewable energy sources as per inputs defined in respective scenarios have high impact on final energy demand of Croatian industry sector. The amounts of energy obtained from utilisation of renewable energy sources are presented on Figure 4.

Figure 4 Final energy demand projections comparison between two Croatian Energy Strategy scenarios (up to 2030) and five designed IED model scenarios (up to 2050)

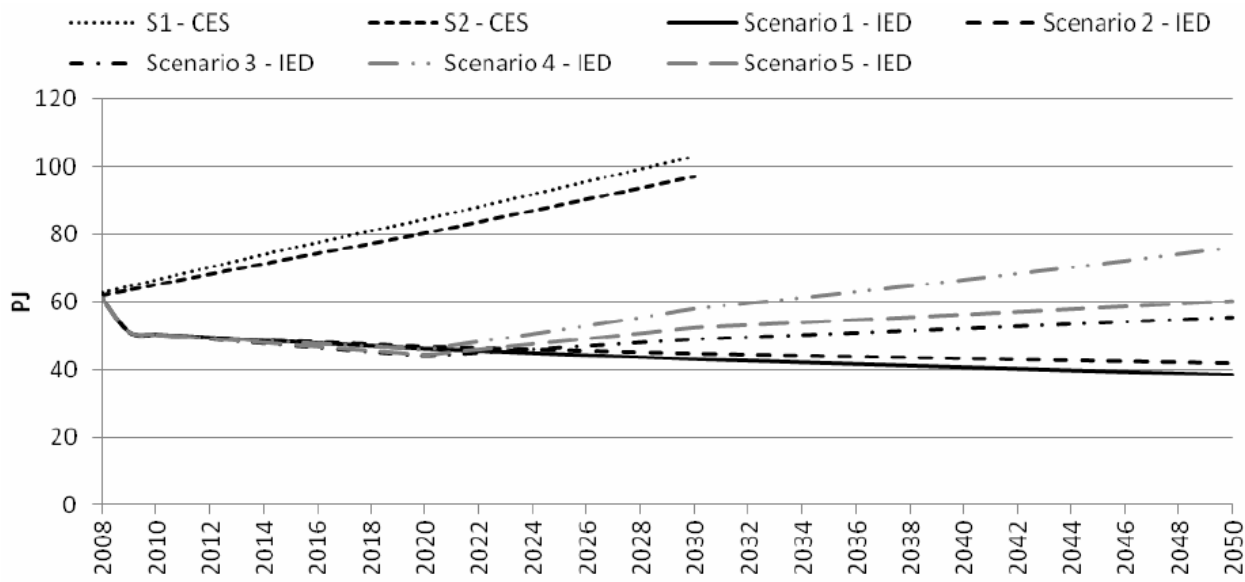

Expected price growth of fossil fuels and electricity will surely impact the day-to-day operation of the industry. As proven from numerous cases across the world, regardless of the sector or activity, renewable energy sources can provide financial and energy savings if properly combined and synchronised with implementation of energy efficiency measures (Pablo del Río, 2010; Marques and Fuinhas, 2011; EIA, 2010). In most cases, energy 'weak spots' are easily spotted in an industrial plant and large savings can be achieved by simple replacement of old components and elements. Exploitation of renewable energy sources, wherever possible and economically viable, should further enhance the impact of implemented energy efficiency measures and highly influence the industry costs to provide a sufficient boost for recovery of the industry. Gradual recovery of the industry sector, as predicted in Scenarios 3, 4 and 5 will be highly influenced by energy efficiency measures and implementation of renewable energy sources to cover the majority of rise in energy consumption. The actual amount of energy produced with renewable energy sources has been calculated based on the input data and previously calculated final energy demand for each year by supplementing each fuel type in respective industry. 
Figure 5 Energy gained from utilisation of renewable energy sources in modelled scenarios

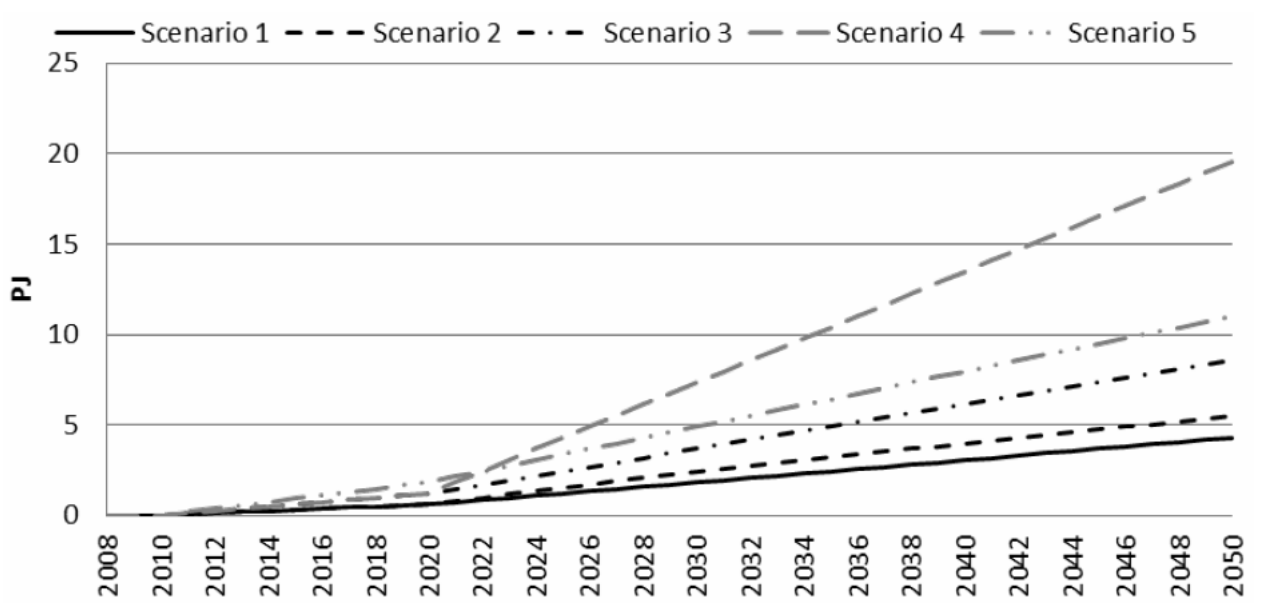

\subsubsection{Final energy demand projection up to 2050}

Final energy projection up to 2050 is shown in Figure 6. The final energy demand in modelled Scenario 1 shows a total IED downfall where the leading industries - food, chemical and construction materials have the sharpest decline. As expected, some types of industries will gradually phase out but such occurrence has not been taken into consideration in the taken period from 2008 to 2050 . The final energy demand in Scenario 1 is 38.38 PJ in 2050 which displays a downfall of final energy demand of $37 \%$ in comparison to 2008 .

Scenario 2 also shows a downfall in energy demand, however, a smaller one than in case of Scenario 1 due to smaller input values of import quantities change and larger quantities in export. The final energy demand in Scenario 2 is larger than in Scenario 1 and is $42.06 \mathrm{PJ}$ in 2050 .

Scenario 3 contains a steady decrease in import quantities and increase in export quantities, meaning increase in domestic production and consequentially increase in final energy demand to 55.42 PJ in 2050. The implementation of energy efficiency measures as envisaged in the scenario is not enough to keep the final energy demand on a steady level without an increase in final energy demand.

Scenarios 4 and 5 have varying value of import change (from -6 to $5 \%$ ) but in comparison to Scenarios 1, 2 and 3 they have large increases in product consumption per capita and export quantities. Energy efficiency measures have a bigger impact in Scenario 5 compared to Scenario 4. The final energy demand of Scenarios 4 and 5 are 76.08 PJ and 60.21 PJ, respectively.

\subsubsection{Final energy mix in modelled scenarios}

Since fossil fuels are still the main energy source it is interesting to provide information on how the energy mix in the modelled scenarios will change. Depending on the input parameters related to energy efficiency but also parameters which determine the overall energy demand of the industry, the contribution of renewable energy sources will cover up to $27 \%$ of the final energy mix depending on the scenario as shown in Figure 7. 
Figure 6 Final energy demand projection in IED scenarios, (a) Scenario 1 (b) Scenario 2 (c) Scenario 3 (d) Scenario 4 (e) Scenario 5
- IRON AND STEEL INDUSTRY
$\square$ NON-FERROUS METALS INDUSTRY
- NON-METALLIC MINERALS INDUSTRY
- CHEMICAL INDUSTRY
$\square$ CONSTRUCTION MATERIALS INDUSTRY $\square$ PULP AND PAPER INDUSTRY
$\square$ FOOD INDUSTRY
$\square$ OTHER MANUFACTURING INDUSTRIES

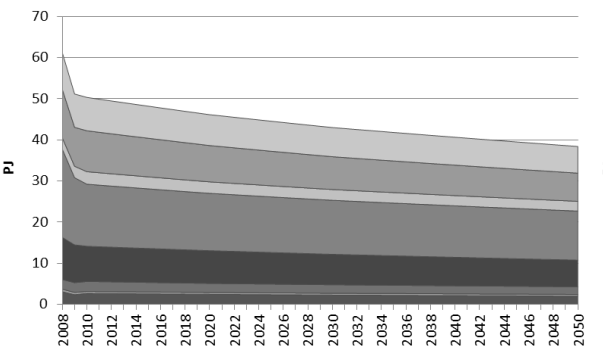

(a)

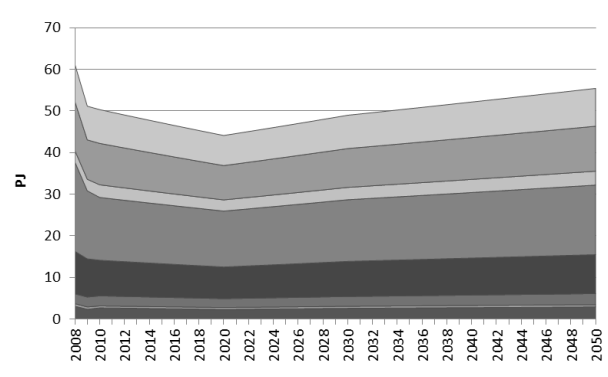

(c)

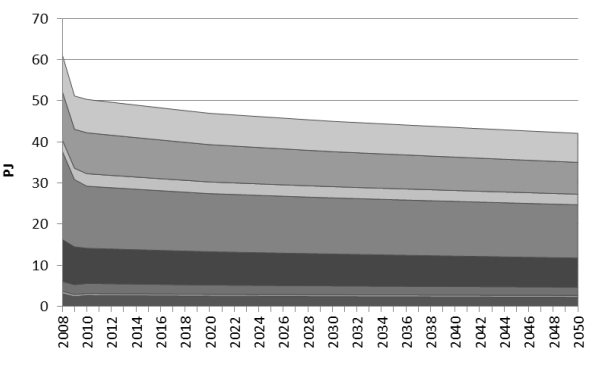

(b)

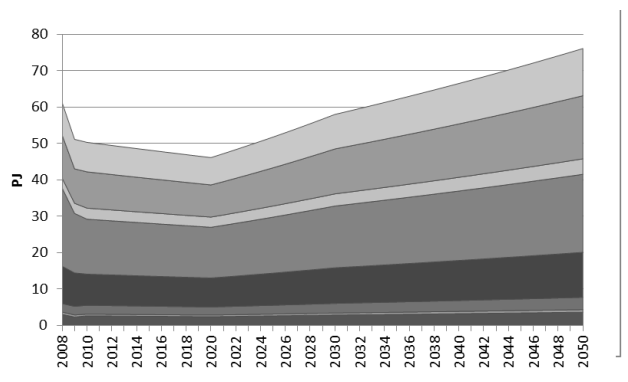

(d)

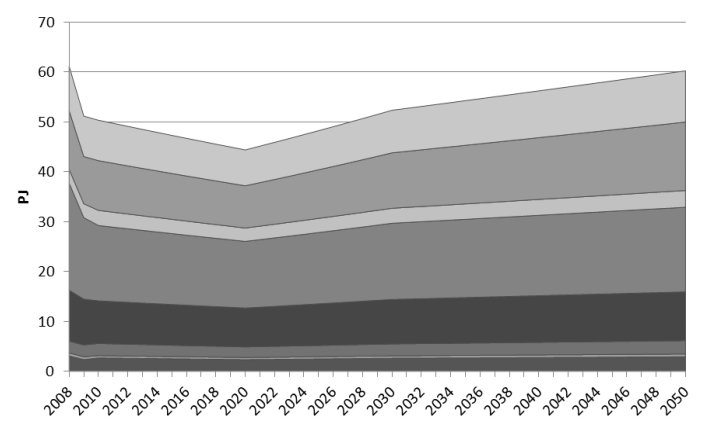

(e)

Figure 7 displays the fuel mix in the case of Scenario 1 in which, according to inputs, electricity has the largest decline due to production of electricity from renewable energy sources. Also, a decline in oil and natural gas can be noticed in 2050 since it has been considered that processes which generate heat from these fuels will be replaced with renewable energy sources or upgraded with heat recovery systems. Final energy fuel mix in Scenario 2 is shown in Figure 8. 
Scenario 2 has slightly higher final energy demand in comparison to Scenario 1 but due to changed input parameters also a bigger contribution of renewable energy sources in final energy mix. A significant reduction in oil consumption and natural gas can be noticed. Also, a decrease in electricity consumption is visible since renewable energy sources are envisaged to contribute to electricity production. Fuel mix for Scenario 3 is shown in Figure 9.

Figure 7 Final energy fuel mix in Scenario 1 (see online version for colours)

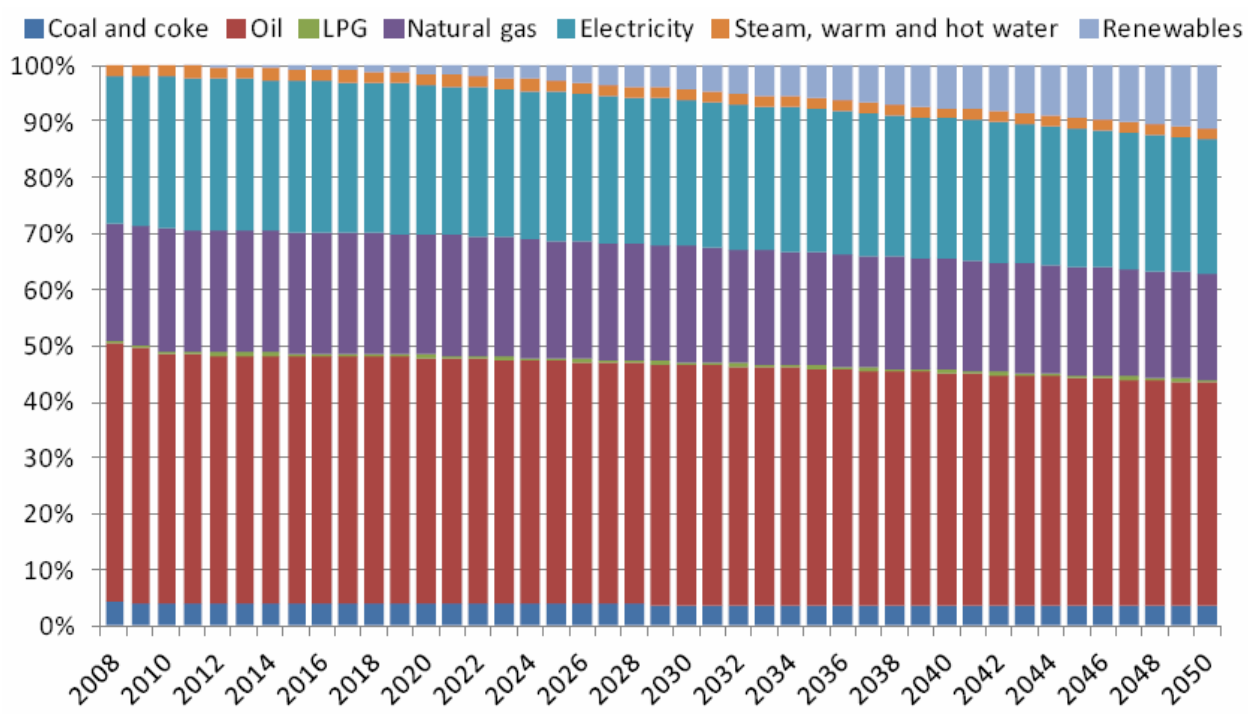

Figure 8 Final energy fuel mix in Scenario 2 (see online version for colours)

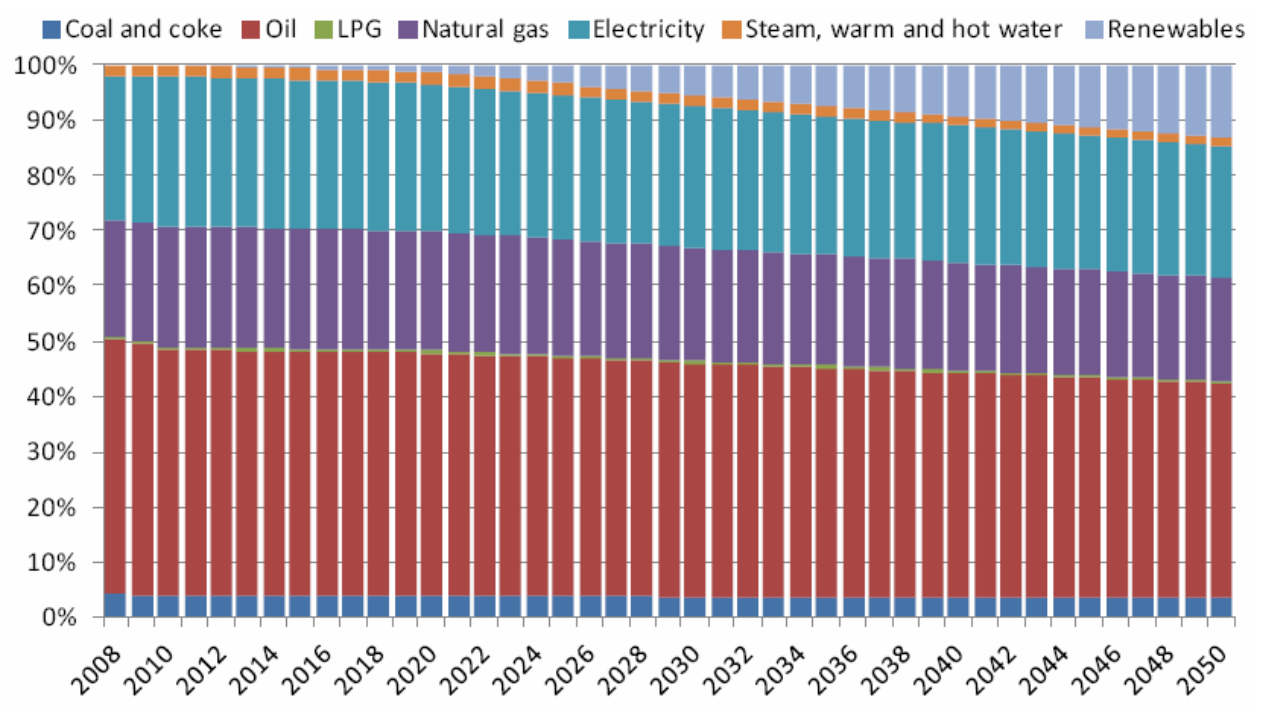

The fuel mix in Scenario 3 shows an increase in share of renewable energy sources in final energy mix in comparison to Scenarios 1 and 2 as determined with the input 
parameters with simultaneous decrease in oil, natural gas and electricity consumption. Figures 10 and 11 present the final energy fuel mix for Scenarios 4 and 5.

Figure 9 Final energy fuel mix in Scenario 3 (see online version for colours)

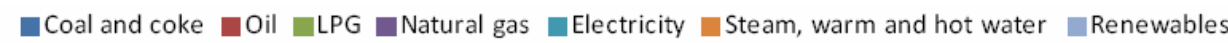

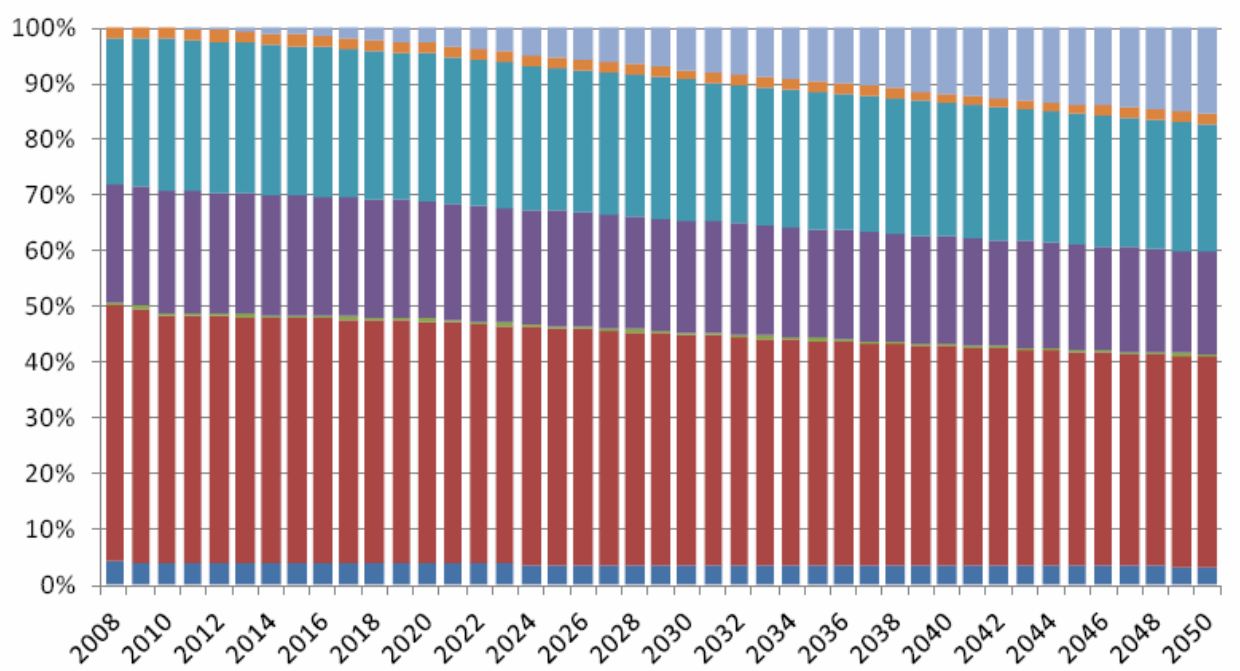

Figure 10 Final energy fuel mix in Scenario 4 (see online version for colours)

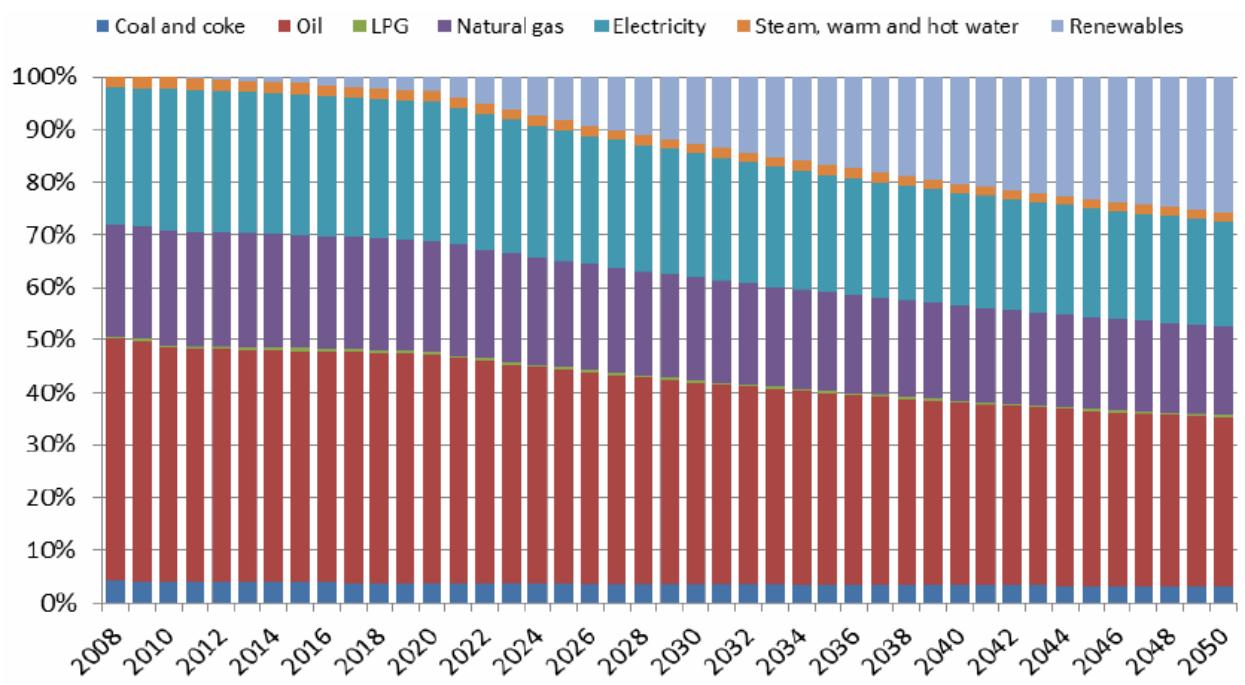

The largest decline in fossil fuel consumption in Scenarios 4 and 5 is expected where the largest growth rates of renewable energy sources are set. Scenarios 4 and 5 have also shown that energy efficiency and renewable sources will play a very important role in the phase of Croatian industry development. If compared with other three scenarios (1,2 and 3) these scenarios show that the rapid growth expected in the future periods can only be supported by strong energy efficiency and renewable energy sources 
measures. In this sense, the policies related to both will have to be properly suited to facilitate the growth and further development.

Figure 11 Final energy fuel mix in Scenario 5 (see online version for colours)

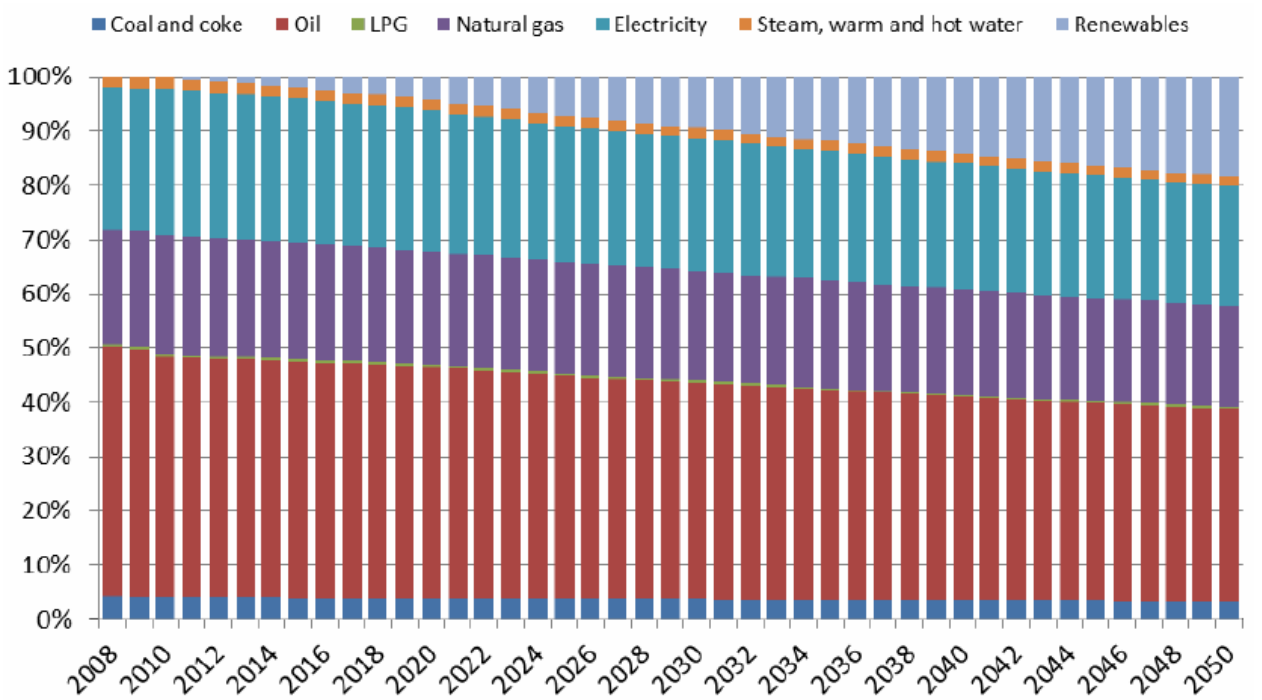

\section{Conclusions}

This model tries to incorporate all relevant factors that directly influence energy consumption, although energy demand modelling of the industry sector was proven to be a challenging task. One of the main challenges is because of the large number of influential factors as well as constantly changing market conditions. The energy consumption in Croatian industry has significantly fallen due to economic crisis. The changes in energy consumption of the Croatian industry have pointed out that the Croatian Energy Strategy already significantly differs from the actual situation. The IED model was developed to assess the future possible outcomes related to energy demand of Croatian industry and to prepare the final energy demand projections for future work on modelling the overall energy situation in Croatia. The IED model is based on the energy data obtained from Croatian energy balance and Croatian Bureau of Statistics. The model was tested on the referent year (2008) and used to predict future production capacities for domestic market and export, as well as import. Each product group was assigned with an energy value obtained from data from Croatian Bureau of Statistics corresponding to its share in the industry. Production capacities and import were then varied according to assumptions in order to assess the outcomes related to industry strengthening or industry phase out. Energy efficiency measures were included in the energy-per-product calculation. Renewable energy sources were included in the calculation upon determining the final energy consumption of each industry.

The IED model is highly flexible, i.e., the input values can be changed to extreme values which results in completely different outcomes. The highly detailed calculation in 
production capacities (according to product groups) also enables slight variations in the final energy demand projections. Each industry can be modelled separately. The model provides final energy demand projections and energy mix.

Even though the Croatian industry is currently in a downfall the future increases in production will cause significant increase in final energy consumption. This increase can be mitigated through implementation of energy efficiency measures and renewable energy sources. Energy efficiency measures have the highest influence on the final energy consumption in the industry since the best way to save energy is not to use it. The difference in the outcomes between Croatian Energy Strategy and the IED model as well as the difference between the current Croatian IED and Energy Strategy clearly points out the importance of more frequent revisions of the Energy Strategy document.

Five scenarios were developed for assessing the final energy demand projections based on different input parameters. The model has shown that Scenarios 1 and 2 have the lowest final energy demand in 2050, $38 \mathrm{PJ}$ and $42 \mathrm{PJ}$, respectively, which is caused by an increase in import, decrease in domestic production, implementation of energy efficiency measures and renewable energy sources. Scenario 3 resulted in a higher final energy consumption of $55 \mathrm{PJ}$ which is caused by higher production capacities for domestic market and export while at the same time reducing the import quantities. Scenarios 4 and 5 have a final energy consumption of $76 \mathrm{PJ}$ and $60 \mathrm{PJ}$, respectively. In both scenarios, the growth is caused by a sharp increase in export capacities and increase in consumption on domestic market.

This model was established on technical observation of the past and current situation in Croatian industry. The development of future situation in the industry is uncertain and depends on many factors and is subject to both technical and economic influences, domestic and foreign. Despite that, industry should be carefully observed and suitable support mechanisms should be implemented in order to support future development.

\section{References}

Bhattacharyya, S.C. and Timilsina, G.R. (2010) 'Modelling energy demand of developing countries: are the specific features adequately captured?', Energy Policy, Vol. 38, No. 4, pp.1979-1990.

Connolly, D., Lund, H., Mathiesen, B.V. and Leahy, M. (2011) 'The first step towards a 100\% renewable energy-system for Ireland', Applied Energy, Vol. 88, No. 2, pp.502-507.

Ćosić, B., Krajačić, G. and Duić, N. (2012) 'A 100\% renewable energy system in the year 2050: the case of Macedonia', Energy, Vol. 48, No. 1, pp.80-87.

Ćosić, B., Markovska, N., Krajačić, G., Taseska, V. and Duić, N. (2011) 'Environmental and economic aspects of higher RES penetration into Macedonian power system', Applied Thermal Engineering, Vol. 43, pp.158-162, DOI: 10.1016/j.applthermaleng.2011.10.042.

Croatian National Energy Strategy (2009) Official Gazette 130/09.

Dutta, M. and Mukherjee, S. (2010) 'An outlook into energy consumption in large scale industries in India: the cases of steel, aluminium and cement', Energy Policy, Vol. 38, No. 11, pp.7286-7298.

Energy in Croatia (2008) Annual Energy Report, Ministry of Economy, Labour and Entrepreneurship, Republic of Croatia.

Fan, Y. and Xia, Y. (2012) 'Exploring energy consumption and demand in China', Energy, Vol. 40, No. 1, pp.23-30. 
Fleiter, T., Fehrenbach, D., Worrell, E. and Eichhammer, W. (2012) 'Energy efficiency in the German pulp and paper industry - a model-based assessment of saving potentials', Energy, Vol. 40, No. 1, pp.84-99.

Fleiter, T., Worrell, E. and Eichhammer, W. (2011) 'Barriers to energy efficiency in industrial bottom-up energy demand models - a review', Renewable and Sustainable Energy Reviews, Vol. 15, No. 6, pp.3099-3111.

Hainoun, A., Seif-Eldin, M.K. and Almoustafa, S. (2006) 'Analysis of the Syrian long-term energy and electricity demand projection using the end-use methodology', Energy Policy, Vol. 34, No. 14, pp.1958-1970.

International Energy Agency (IEA) (2010) World Energy Outlook 2010.

Klemeš, J., Varbanov, P., Pierucci, S. and Huisingh, D. (2010) 'Minimising emissions and energy wastage by improved industrial processes and integration of renewable energy', Journal of Cleaner Production, Vol. 18, No. 9, pp.843-847.

Krajačić, G., Duić, D. and da Graça Carvalho, M. (2011) 'How to achieve a 100\% RES electricity supply for Portugal?', Applied Energy, Vol. 88, No. 2, pp.508-517.

Liu, W., Lund, H., Mathiesen, B.V. and Zhang, X. (2011) 'Potential of renewable energy systems in China', Applied Energy, Vol. 88, No. 2, pp.518-525.

Marques, A.C. and Fuinhas, J.A. (2011) 'Do energy efficiency measures promote the use of renewable sources?', Environmental Science \& Policy, Vol. 14, No. 4, pp.471-481.

Pablo del Río (2010) 'Analysing the interactions between renewable energy promotion and energy efficiency support schemes: the impact of different instruments and design elements', Energy Policy, Vol. 38, No. 9, pp.4978-4989.

Paulus, M. and Borggrefe, F. (2011) 'The potential of demand-side management in energy-intensive industries for electricity markets in Germany', Applied Energy, Vol. 88, No. 2, pp.432-441.

Segurado, R., Krajačić, G., Duić, D. and Alves, L. (2011) 'Increasing the penetration of renewable energy resources in S. Vincente, Cape Verde', Applied Energy, Vol. 88, No. 2, pp.466-472.

Suganthi, L. and Samuel, A.A. (2012) 'Energy models for demand forecasting - a review', Renewable and Sustainable Energy Reviews, Vol. 16, No. 2, pp.1223-1240.

Szabó, L., Soria, A., Forsström, J., Keränen, J.T. and Hytönen, E. (2009) 'A world model of the pulp and paper industry: demand, energy consumption and emission scenarios to 2030', Environmental Science \& Policy, Vol. 12, No. 3, pp.257-269.

US Energy Information Administration (EIA) (2010) Levelized cost of New Generation Resources in the Annual Energy Outlook 2011.

Vuk, B., Vukman, S., Karan, M., Fabek, R., Zivkovic, S., Maricevic, M. et al. (2009) 'Annual energy report - energy in Croatia', Ministry of Economy, Labour and Entrepreneurship, Zagreb, Croatia. 